\title{
WIRELESS SURVEILLANCE CAMERA WITH AMC (AUTOMATIC MOTION CAPTURES) SYSTEM
}

\author{
Ageng Setiani Rafika ${ }^{1}$ \\ Asep Saefullah ${ }^{2}$ \\ Andri Ahmad Gozali ${ }^{3}$ \\ Dosen STMIK Raharja Jurusan Sistem Komputer ${ }^{1}$, Alumni STMIK Raharja Jurusan Teknik \\ Informatika $^{2}$, Mahasiswa STMIK Raharja Jurusan Sistem Komputer ${ }^{3}$ \\ Email: agengsetianirafika@raharja.info,asep.saefullah@raharja.info, \\ andrizali@raharja.info
}

Diterima:2 Agustus 2015/ Disetujui : 2 September 2015

\begin{abstract}
Nowadays, utilizing surviellence cameras was very popular because is user friendly and it has many usefull as a monitoring and as a part of security system at home, institution, office, etc. The existing surviellence camera using computer as a control system and as a media storage so it's need a energy and high cost for implementation. Surveillance cameras are designed using the Raspberry Pi B, PIR sensor, webcam Logitech C 170, SD Card, Twitter, Raspbian operating system, and python programming. Automatic input data is performed by PIR sensor that will be detected human around of range area frequently. Output 3.3 - 5 volt (High) will be generated when sensor detected the human around of range area. Otherwise 0 volts output ( Low) will be generated when sensor not detected the human around of range area frequently. Then, The input will be processing by Raspberry Pi using python programming that has made to a command to capture or not.implemetation outcome is a surveillance camera that will capture image in (.jpg) format when the input system detected human around of range frequently. Capture result will save to SD Card that have integrated system. Then the sistem will provide immediately report the situation in a real-time notification through a twitter application device.
\end{abstract}

Keywords: Raspberry Pi, Raspbian, Python, USB Webcam, PIR sensor, Twitter.

\begin{abstract}
ABSTRAK
Saat ini pengaplikasian kamera pengawas sudah sangat populer karena mudah digunakan dan pemanfaaantnya sangat banyak terutama sebagai sistem pengawasan dan sebagai bagian dari sistem keamanan rumah, institusi, kantor dan lain-lain. Eksistensi kamera pengawas yang ada saat ini menggunakan komputer sebagai pengontrol dan sebagai media penyimpanan (storage) sehingga membutuhkan daya dan biaya yang mahal dalam pemasangannya. Kamera pengawas yang dirancang menggunakan Raspberry Pi tipe B, Sensor PIR, Webcam Logitech C 170, SD Card, Twitter, OS Raspbian, serta Bahasa Pemrograman Python. Input data akan dilakukan sensor PIR secara otomatis yang mendeteksi manusia yang berada di area sekitar jangkaunnya secara berkala. Output 3.3 - 5 volt (high) akan dihasilkan apabila sensor mendeteksi manusia berada di area sekitar jangkaunnya. Sebaliknya Output 0 volt (Low) akan dihasilkan ketika tidak mendeteksi gerakan manusia di area sekitar jangkaunnya. Kemudian input tersebut akan diproses kembali oleh Raspberry Pi sebagai input untuk melakukan proses pengambilan atau tidaknya
\end{abstract}


pada gambar. Hasil implementasinya adalah berupa kamera pengawas yang akan melakukan pengambilan gambar dalam format (.jpg) secara terus-menerus apabila sistem input kamera pengawas mendeteksi manusia yang berada di area sekitar jangkauannya. Hasil pengambilan gambar disimpan ke SD Card yang sudah terintegrasi sistem. Kemudian sistem tersebut akan memberikan report dengan notifikasi secara real-time melalui aplikasi twitter.

\section{Kata Kunci :Raspberry Pi, Raspbian, Python, USB Webcam, Sensor PIR, Twitter}

\section{PENDAHULUAN}

Pengawasan (surveillance) adalah aspek yang secara langsung mendukung peran penting untuk beberapa bidang kehidupan manusia.Eksistensi dari pengawasan didasari oleh keamanan yang lemah (low monitoring security).Faktor keterbatasan fisik manusia menjadi indikator kelemahan pengawasan.Seiring kemajuan teknologi, mulai dibangun sistem keamanan yang berbasis kendali elektronika dengan sistem pengawasan otomatis (automatic monitoring system).Monitoring keamanan yang populer yaitu menggunakan kamera pengawas (survaillance camera) melalui monitoring jarak jauh dengan wireless.Pemanfaatan monitoring keamanan secara progresif dan efektif adalah selalu didasarkan pada kebutuhan pengawasan secara berkala dan merekam segala rutinitas aktivitas yang sedang berlangsung dilokasi kejadian dengan indikasi ketika terjadi suatu hal yang tidak diinginkan dapat ditindak-lanjuti secara cepat (real-time).Dengan demikian, kapabilitas kamera difokuskan untuk mengatasi situasi yang dihadapi.Artinya, dari segi monitoring untuk menjawab problem yang terjadi, muncul ide untuk mengeksplorasi fungsi kamera.

Monitoring keamanan dengan kamera sebagai pegawas telah banyak diterapkan, diantaranya, yaitu CCTV (Closed Circuit Television) dan IP (Internet Protocol) kamera.Pada dasarnya, kamera CCTV/IP kamera bersifat tertutup bagi publik (private network), yang tidak dapat di akses dengan bebas kecuali oleh pihak-pihak yang memiliki otoritas. Implementasi kamera CCTV/IP kamera sebagai penangkap citra digital berupa rekaman (video/image record) dapat mempermudah untuk mengawasi bagian dalam-luar ruangan selama 24 jam sehingga mengurangi tugas penjagaan oleh operator dari tindak kriminal. Namun, dalam pemasangannya perlu hardware tambahan yang dipasang pada komputer selain dari kamera sendiri, yaitu DVR card atau TV tuner.Selama ini, CCTV/IP kamera menggunakan NVR (Network Video Recorder) sebagai server dan media penyimpanan.Permasalahannya, NVR yang cenderung mahal belum terjangkau oleh seluruh kalangan, disamping itu, jenis komputer yang digunakan yaitu komputer dengan spesifikasi tinggi.

Kamera webcam dapat dipakai sebagai alternatif karena harga yang relatif murah dan efektivitas yang bergantung pada perangkat pengendalian sehingga sangat fleksibel.Webcam itu sendiri dimanfaatkan sebagai sistem monitoring keamanan untuk streamingvideo atau motion captures secara tersembunyi. Selain itu, webcam dapat dengan mudah berkomunikasi dalam sebuah device komputer melalui USB (Universal Serial Bus) port.

Ada beberapa permasalahan lain jika webcam terus merekam secara real-time meskipun tidak ada gerakan yang terjadi dilokasi kejadian, yaitu penggunaan memori yang sia-sia, sehingga pada penyimpanan (media storage) membuat pemakaian menjadi sangat besar, maka alternatif untuk mengatasinya adalah mengaplikasikan perangkat elektronika yang akan meningkatkan efisiensi kamera sehingga kamera hanya mendeteksi gerakan obyek.

Operating unit diperlukan sebagai implementasi kerja alat yang biasanya 
dikenal CPU (Central Processing Unit). Dalam penggunaannya, CPU dapat membutuhkan daya dan biaya cukup besar dalam suatu proses (image processing). Selain itu, apabila dilihat pada kapasitas ruangan, CPU lebih memakan tempat.Cara untuk mengatasi masalah itu adalah dengan teknologi berbasis SBC (Single Board Computer).SBC adalah komputer mini dengan konsumsi daya rendah sebesar 5 Volt.Salah satu SBC yang termasuk hasil dalam perkembangan teknologi komputer, diantaranya yang populer yaitu Raspberry Pi.Teknologi Raspberry $\mathrm{Pi}$ mulai digunakan untuk sebuah proyek dan penelitian teknologi. Karena itulah pada teknologi Raspberry Pi telah mendukung berbagai macam hardware dari berbagai proyek dan penelitian, diantaranya adalah kamera yang banyak digunakan untuk mendukung proyek pengawasan (surveillance) terhadap keamanan suatu ruangan,

baik ruangan terbuka, seperti: lokasi parkir dan ruangan tertutup, seperti: ruang instansi, yang akan meringankan kerja tugas monitoring dengan bantuan operator secara manual.

\section{PERMASALAHAN}

Dalam penggunaannya, kamera CCTV/IP kamera merekam setiap saat walaupun tidak ada aktivitas yang berlangsung. Hal ini merupakan kendala karena data-data yang tidak penting akan ikut tersimpan. Kendala lainnya adalah interval waktu dari perangkat kamera dalam memberikan informasi tentang keadaan yang sedang berlangsung saat ini.Kamera mungkin tidak dapat mengirim notifikasi langsung terhadap situasi yang terjadi dalam suatu ruangan maka kamera yang terpasang akan merekam apapun, sehingga user tidak menerima informasi secara real-time untuk bisa dibuka kapanpun dan dimanapun, melainkan kamera akan menyimpannya terlebih dahulu dan baru dapat dilihat oleh user.

\section{LITERATURE REVIEW}

Berikut ini merupakan penelitian yang sudah dilakukan dan mempunyai kolerasi searah dengan penelitian yang akan dibahas dalam Penelitian ini, diantara lain adalah:

1. Penelitian yang dilakukan oleh Bustanul Arifin yang berjudul "Aplikasi Sensor Passive Infrared (PIR) Untuk Pendeteksi Makhluk Hidup Dalam Ruang." pada tahun 2013. Penelitian ini membahas mengenai pemanfaatan sensor gerak yang menggunakan infrared secara pasif atau yang lebih dikenal dengan sensor PIR (Passive Infra Red). Dalam penelitian ini diteliti bagaimana cakupan pendeteksi sensor, posisi sensor yang dapat menjangkau cakupan terluas, serta makhluk hidup atau benda apa saya yang bisa dideteksi oleh sensor ini. Berdasarkan penelitian yang dilakukan di Laboratorium Mikroprosesor Teknik Elektro Unissula dengan menggunakan 4 buah sensor PIR KC7783R didapatkan hasil bahwa sensor dapat menjangkau cakupan terluas ketika diletakan di ketinggian $200 \mathrm{~cm}$ dari lantai dengan sudut kemiringan $75^{\circ}$. Jarak 500 meter merupakan titik terjauh untuk mendeteksi manusia, sedangkan untuk mendeteksi tikus maksimal $180 \mathrm{~cm}$, kucing $230 \mathrm{~cm}$, dan juga nyala api lilin $210 \mathrm{~cm}$. Perubahan suhu tidak berpengaruh secara signifikan terhadap pendeteksi sensor PIR (Passive Infra Red) dari penelitian ini [1].

2. Penelitian yang dilakukan oleh Therzian R. Perkasa yang berjudul "Rancang Bangun Pendeteksi Gerak Menggunakan Metode Image Subtraction Pada Single Board Computer (SBC)." pada tahun 2014. 
Penelitian ini membahas mengenai kamera pengawas yang mendeteksi dengan menggunakan Raspberry Pi dengan menerapkan metode Image Substraction. Image Subtraction yaitu pengurangan atau mencari perbedaan antar frame awal $\left(\mathrm{f}_{\mathrm{i}}\right)$ dengan frame sebelumnya $\left(\mathrm{f}_{\mathrm{i}}-1\right)$ sehingga gerakan yang ada dalam kawasan pantauan kamera dapat dideteksi dan direkam ke dalam single board computer atau minicomputer biasanya dikenal Raspberry Pi [7].

3. Penelitian yang dilakukan oleh Nugroho Amarudita yang berjudul "Raspberry Pi sebagai Pengendali Web Camera Melalui Web Browser Untuk Meningkatkan Keamanan Pada PT Medarya Menara Lestari." pada tahun 2012. Penelitian ini, membahas mengenai kamera pengawas berbasis Raspberry $\mathrm{Pi}$, dimana kamera yang dapat bergerak, sebagai penggeraknya adalah motorstepper. Pergerakan kamera ini, masih manual karena memerlukan input petugas, dalam menggerakan suatu kamera. Sistem kendali gerakan kamera dibatasi, hanya ke kiri-kanan dan ke atas-bawah [4].

4. Penelitian yang dilakukan oleh Hendra Kusumah yang berjudul "Surveillance Camera Robot" pada tahun 2013. Penelitian ini membahas pengontrolan pada robot dengan kamera berbasis Raspberry $\mathrm{Pi}$, dimana sistem sangat kompleks karena pengendali kamera dilakukan sepenuhnya pada robot. Sehingga, pergerakan kamera masih manual karena harus menunggu inputoperator dalam menggerakan robot [3].

5. Penelitian yang dilakukan oleh Nursalim yang berjudul "Smartphone Control Interface Melalui Web Berbasis Raspberry Pi Pada Kantor Kelurahan Cibogo Di Daerah Cisauk
Kabupaten Tangerang." pada tahun 2014. Penelitiian ini membahas tentang sistem kendali ruangan dengan mengontrol kipas dan lampu menggunakan smartphone berbasiskan Raspberry $\mathrm{Pi}$ dan mengontrolnya melalui web. Sehingga, pengontrolan memerlukan input dari seorang user untuk mengontrol perangkat kipas dan lampu secara manual [5].

Dari beberapa sumber literatur review diatas, bisa diketahui bahwa pemanfaatan sensor Passive Infra Red (PIR) KC7783R yang memiliki jarak yang cukup jauh sebagai alat pendeteksi gerak sudah banyak menjadi pembahasan, meski demikian pemanfaatan sensor PIR dalam monitoring keamanan ruangan secara otomatis (automatic monitoring system) yang masih kurang perhatian dalam penelitiannya. Selain itu, terdapat beberapa kekurangan pada masing-masing penelitian tersebut, khususnya implementasi di kamera dan pengendalian device pada Raspberry Pi.Kamera yang terus-menerus merekam dan sistem kontrol yang masih manual menjadi permasalahan dalam penelitian diatas.tujuan dalam penelitian ini yaitu untuk menutupi kekurangan umum yang ada pada penelitian sebelumnya antara lain dengan menerapakan fungsi dari kamera agar dapat melakukan sistem pengawasan (survaillance) dan keamanan (security) secara real-time tanpa perlu inputan oleh operator atau secara otomatis bisa dimonitor oleh sensor pendeteksi gerak. Penelitian ini termasuk ke dalam jenis penelitian terapan karena berfokus untuk mencari solusi tentang permasalahan tertentu sehingga hasil dari penelitian ini dapat langsung diterapkan dan dimanfaatkan misalnya; untuk kepentingan instansi dalam ruangan kasir.

\section{PEMECAHAN MASALAH}


Mobilitas manusia yang semakin cepat akibat dari aktifitas yang dilakukan di era teknologi digital saat ini, menjadikan manusia membutuhkan sebuah sistem monitoring keamanan yang mempunyai ciri mobile technology, yaitu dalam mendapatkan informasi ataupun pengaksesannya menggunakan cara yang mudah, cepat dan tidak mengganggu pekerjaan. Salah satu contohnya, yaitu ditemukannya teknologi smartphone yang sesuai dengan kebutuhan manusia untuk berkomunikasi jarak jauh menggunakan tethring pada perangkat smartphone yang terkoneksi internet (Wi-Fi). Untuk dapat mendukung sistem automatic motion captures digunakan alat yang dapat merekam gambar (capture) secara realtime, yaitu dengankamera webcam. Webcam umum digunakan pada perangkat PC (Personal Computer) karena memiliki Port USB untuk dihubungkan ke PC. Sedangkan, PC memerlukan daya dan biaya yang besar untuk melakukan proses (image processing). Cara untuk mengatasinya ialah dengan teknologi SBC yang populer yaitu Raspberry Pi.Meskipun Raspberry Pi mempunyai fisik seperti Arduino (microcontroller) namun pada kenyataanya berbeda dengan mikrokontroler kebanyakan, dan sebenarnya Raspberry Pi lebih seperti komputer (minicomputer).Raspbery $\mathrm{Pi}$ mempunyai dua tipe yaitu A dan B. Adapun untuk memahami perbandingan tipe A dan B, dapat dilihat di dalam tabel 1 [6]:

Tabel. 1 Spesifikasi Raspberry Pi Model A dan Model B

\begin{tabular}{l|l|l}
\hline Fitur Teknis & Model A & $\begin{array}{l}\text { Model } \\
B\end{array}$ \\
\hline $\begin{array}{l}\text { SoC (System } \\
\text { on Chip) }\end{array}$ & \multicolumn{3}{|c}{ Broadcom BCM2835 } \\
\hline CPU & $\begin{array}{l}\mid c \\
\text { ARM1176JZ-F }\end{array}$ \\
\hline GPU & $\begin{array}{l}\text { Dual Core VideoCore IV } \\
\text { Multimedia } \\
\end{array}$ & Processor Co- \\
\hline Memory & $256 \quad M B$ & 512 \\
\hline
\end{tabular}

\begin{tabular}{|c|c|c|}
\hline & SDRAM & $\begin{array}{l}M B \\
S D R A \\
M \\
\end{array}$ \\
\hline USB 2.0 & 1 & 2 \\
\hline Video Out & \multicolumn{2}{|c|}{$\begin{array}{l}\text { Composite RCA (PAL } \\
\text { and NTSC), HDMI }\end{array}$} \\
\hline Audio Out & \multicolumn{2}{|c|}{ 3.5mm jack, HDMI } \\
\hline Storage & \multicolumn{2}{|l|}{$\begin{array}{l}\text { SD/MMC/SDIO } \\
\text { Slot }\end{array}$} \\
\hline Network & No Port & $\begin{array}{l}\text { RJ45 } \\
\text { Ethern } \\
\text { et }\end{array}$ \\
\hline $\begin{array}{l}\text { Peripheral } \\
\text { Connectors }\end{array}$ & \multicolumn{2}{|c|}{$\begin{array}{l}8 x G P I O, U A R T, I 2 C \text { bus, } \\
\text { SPI bus }\end{array}$} \\
\hline $\begin{array}{l}\text { Power } \\
\text { Source }\end{array}$ & \multicolumn{2}{|c|}{$\begin{array}{l}\text { 8xGPIO, UART, I2C bus, } \\
\text { SPI bus }\end{array}$} \\
\hline
\end{tabular}

Dalam penelitian ini, menggunakan Raspberry Pi model B karena mempunyai 2 Port USB dan memory yang cukup besar.Port 1 digunakan untuk jaringan etthernet dan Port 2 digunakan untuk kamera webcam. Untuk lebih jelasnya, dibawah ini komponen hardwareRaspberry Pi B dan penjelasan port-nya yang dapat dilihat pada gambar 1 [2]:

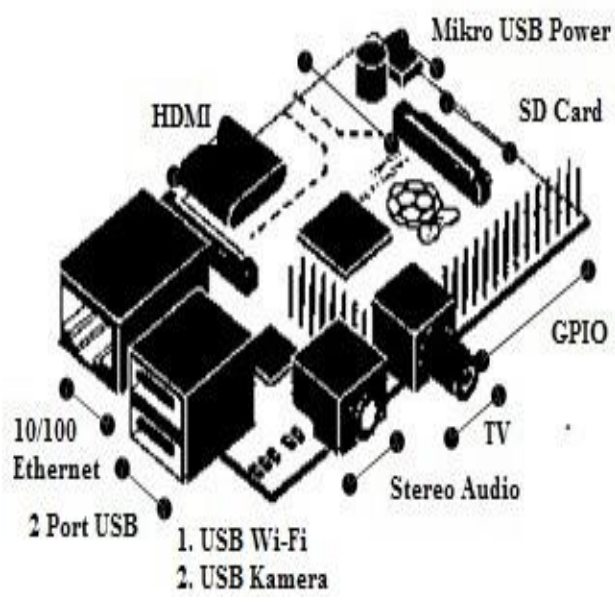

Gambar 1. Komponen Hardware Raspberry Pi B

Dalam penggunaannya, Raspberry $\mathrm{Pi}$ memiliki beberapa keunggulan seperti low power dan relatif mudah apabila dihubungkan dalam perangkat USB Wi-fi 
dan Webcam, dibandingkan dengan mikrokontroler (arduino).Alasan memilih webcam, karena relatif murah daripada kamera pengawas seperti IP kamera dan CCTV yang beredar dipasaran.Salah satu webcam yang dipakai dalam penelitian ini adalah webcameralogitech C170.

Untuk spesifikasi, yaitu: video calls 640x480, captures 1024x768, photos 5 megapixels. Adapun spesifikasi webcam logitech C170 dapat dilihat pada gambar 2, dibawah ini [3]:

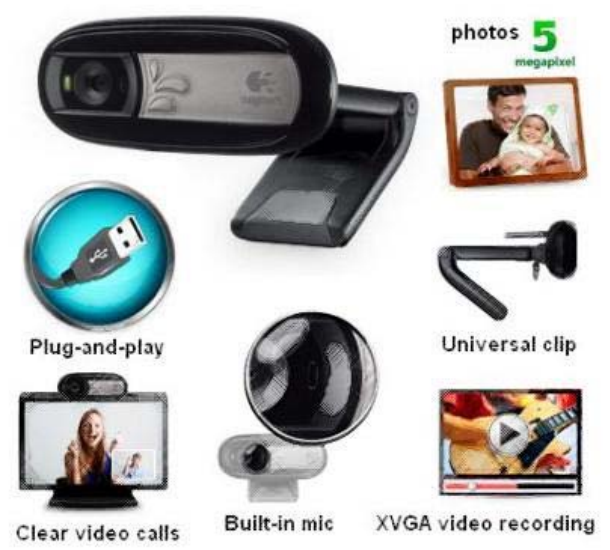

Gambar 2. Fitur Webcam Camera C170

Untuk meningkatkan fungsi kamera yang dapat mengidentifikasi obyek bergerak (motion detector) yaitu dengan merancang alat yang hanya melakukan motion captures, sehingga dapat menghemat media penyimpanan dalam melakukan tugas kepengawasan. Selain itu, pada sistem tersebut harus dilakukan secara otomatis tanpa bantuan input dari operator. Untuk mengatasi hal itu digunakanlah sensor PIR (Passive Infrared Receiver).Pada proyek ini menggunakan sensor PIR KC7783R. Jika PIR mendeteksi gerakan akan merubah nilai Output $0-5 \mathrm{~V}$. tegangan operasional antara 5-20VDC. Sensivitas dan pada waktu tunda dapat disesuaikan dari potensiometer pada sensor.Sensor PIR mempunyai 3 pin, diantaranya adalah pin yang terhubung VCC, GND, dan pin untuk Sinyal Output. PIR merupakan sensor yang berbasis infrared.Akan tetapi, tidak seperti sensor infrared yang terdiri dari IR LED dan fototransistor.Sensor ini tidak memancarkan sinar apapun sesuai namanya passive, sensor ini hanya merespon pancaran energi sinar infrared pasif yang dimiliki oleh tubuh manusia.adapun untuk mengetahui jarak dari sensor PIR yang mampu dijangkau oleh kamera webcam C170 bisa dilihat dari gambar 3 dibawah ini [2]:

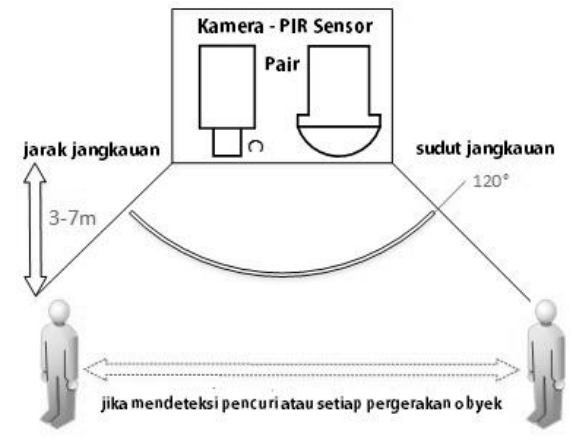

Gambar 3. Figure Kamera dan Sensor
PIR

Sistem deteksi gerak dari PIR akan secara otomatis melakukan (motion caputes) dengan menggunakan webcam. Lalu, kamera webcamakan mengirim informasi melalui aplikasi internet dalam perangkat smartphone yang terkoneksi dengan jaringan wireless. Pada proyek ini aplikasi yang digunakan adalah twitter.Alasannya, twitter dalam sektor pemakaiannya bersifat publik yang dapat melakukan tweet dan share kepada seseorang.Wireless yang digunakan agar dapat terhubung melalui twitter yaitu TP-Link WN722N. TP-Link WN722N memiliki jarak lebih jauh daripada komunikasi dengan bluetooth. Adapun spesifikasi wireless TP-LINK WN722N, bisa dilihat dari gambar 4 dibawah ini: 


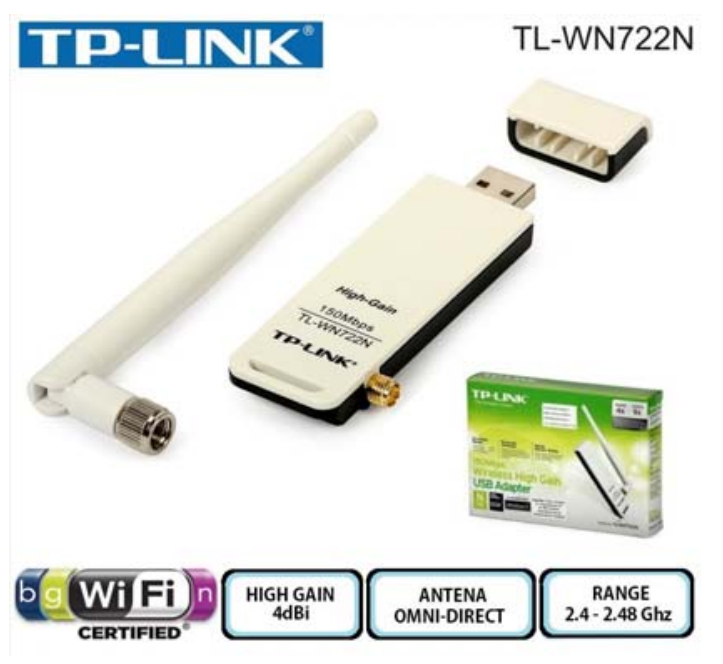

Gambar 4. TP-LINK (TL-WN722N)

\section{IMPLEMENTASI}

\section{Flowchart Sistem}

Adapun alur cara kerja sistem alat secara keseluruhan untuk menjelaskan tentang bagaimana surveillance camera yang dapat capture otomatis via twitter secara real-time saat ada gerak ditunjukan pada flowchart yang dapat dilihat pada gambar 5 dibawah ini:

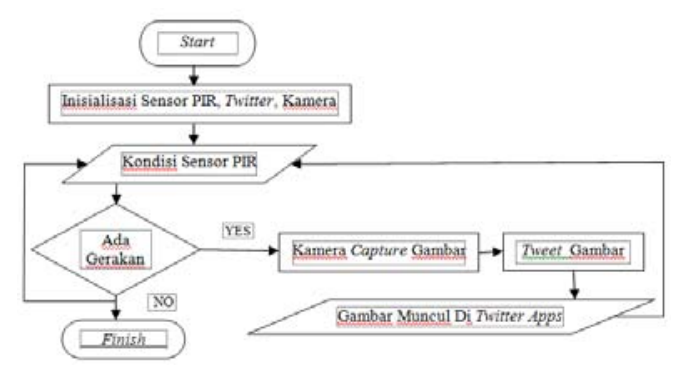

\section{Gambar 5. Flowchart Sistem AMC Wireless Surveillance Camera}

\section{Perancangan Hardware}

Perancangan hardware untuk merancang komponen surveillance dengan kamera ini menggunakan perangkat Raspberry $\mathrm{Pi}$ sebagai modul untuk melakukan suatu proses, Wireless dongle TP-LINK TL-
WN722N sebagai komunikasi serial dengan smartphone,

PIR KC7783R sensor digunakan sebagai modul pendeteksi obyek bergerak secara pasif.

Modul webcam C170 sebagai surveillance camera dengan menangkap (motion capture) berdasarkan ada dan tidak terdeteksinya obyek bergerak (motion detection) melalui PIR.Output 3.3 - $5 \mathrm{~V}$ (high) akan dihasilkan jika sensor mendeteksi obyek di area sekitar jangkauan. Dan output $0 \quad \mathrm{~V}$ (low) dihasilkan ketika sensor tidak mendeteksi obyek di area sekitar jangkauan. untuk mengetahui rancangan dari hardware sistem dapat dilihat pada gambar 6 dibawah ini:

\section{Rangkaian Keseluruhan Sistem}

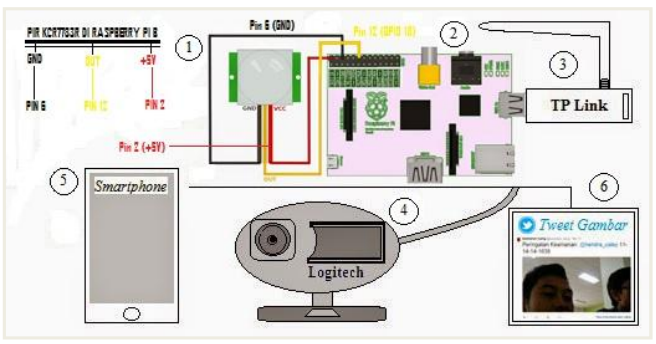

Gambar 6. Diagram Blok Keseluruhan Alat

Dalam proyek ini diperlukan beberapa komponen penunjang dan perangkat pada elektronika seperti Raspberry Pi B sebagai mini komputer (Single Board Processor) dan kendali sebuah sistem yang terintegrasi dengan perangkat suatu hardware dan software. Selain itu, komponen lainnya, yaitu PIR KCR7783R sebagai sensor pendeteksi gerakan dan perangkat smartphone sebagai alat monitoring melalui twitter. Smartphone tersebut harus mendukung hotspot yang dapat di tethring menggunakan TP-LINK TL-WN722N.Sehingga, dapat dikendalikan secara nirkabel (wireless) melalui Kamera Webcam C170.

Agar mudah memahami dibawah ini akan ditunjukan diagram blok rangkaian hardware dari keseluruhan alat dan disertai 
penjelasannya dapat dilihat dalam tabel 2 dibawah ini:

Tabel 2. Rangkaian Hardware Keseluruhan Alat

\begin{tabular}{|c|c|c|}
\hline No & Nama & Keterangan \\
\hline 1 & $\begin{array}{l}\text { PIR } \\
\text { KCR7783 } \\
\text { R }\end{array}$ & 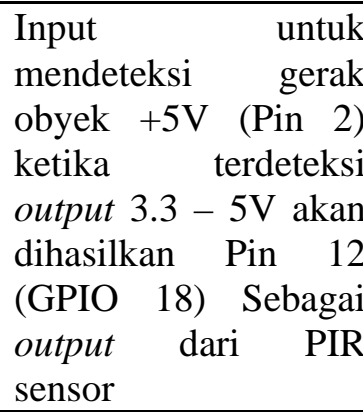 \\
\hline 2 & $\begin{array}{l}\text { Raspberry } \\
\text { Pi B }\end{array}$ & $\begin{array}{l}\text { Proses untuk input } \\
\text { dan outputdevice } \\
\text { elektronika, Platform } \\
\text { memasukan program } \\
\text { di dalam SD card, } \\
\text { serta pusat sistem } \\
\text { kontroling yang berisi } \\
\text { program }\end{array}$ \\
\hline 3 & $\begin{array}{l}\text { TP-LINK } \\
\text { TLWN722 } \\
\mathrm{N}\end{array}$ & $\begin{array}{lr}\text { Modul } & \text { dengan } \\
\text { komunikasi } & \text { serial } \\
\text { secara nirkabel } & \end{array}$ \\
\hline 4 & $\begin{array}{l}\text { Webcam } \\
\text { Logitech } \\
\text { C170 }\end{array}$ & $\begin{array}{lr}\begin{array}{l}\text { Surveillance } \\
\text { berbasiskan } \\
\text { captures }\end{array} & \begin{array}{r}\text { kamera } \\
\text { image }\end{array} \\
\end{array}$ \\
\hline 5 & $\begin{array}{l}\text { Smartphon } \\
e\end{array}$ & $\begin{array}{l}\text { Display } \\
\text { monitoringsystem } \\
\text { untuk menerima data }\end{array}$ \\
\hline 6 & $\begin{array}{l}\text { Aplikasi } \\
\text { Twitter }\end{array}$ & $\begin{array}{l}\text { Memberikan } \\
\text { notifikasi dalam } \\
\text { device smartphone }\end{array}$ \\
\hline
\end{tabular}

\section{Konfigurasi Wireless}

Akses internet tanpa ethernet atau diluar ruangan dapat dikoneksikan dari device android phone karena terdapat hotspot sebagai koneksi internet untuk Raspberry $P i$ dan sebagai tethring untuk surveillance camera dengan Wi-fi Dongle TP-Link TLWN722N. Untuk mudah memahami konfigurasi wireless, dapat dilihat pada gambar 7 dibawah ini: sudo nano /etc/netivork/irterfaces

Gambar 7.kode menampilkan IP Address

Untuk mengaktifkan kode program awal, dapat menuliskan iface etho inet dhcp. Supaya IP dinamis dapat dirubah ke dalam static, yang dapat dilihat pada gambar 8 dibawah ini:

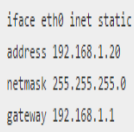

Gambar 8. Konfigurasi device dengan IP Static

\section{Konfigurasi GPIO}

Library GPIO ini yang akan memberikan jalur pengontrolan Pin Raspberry Pi B. Kemudian, nantinya dapat dihubungkan dengan sensor PIR. Sensor ini memiliki tiga pin terminal dengan terdiri dari output pin 12 (GPIO 18), VCC pin $2(+5 \mathrm{~V})$, pin 6 (Ground).

Berikut ini kode program yang digunakan untuk konfigurasi pin GPIO Raspberry $\mathrm{Pi}$ $B$ yang diawali dari instalasi python-dev dan python-rpi.gpio sesuai gambar 9 dibawah ini:

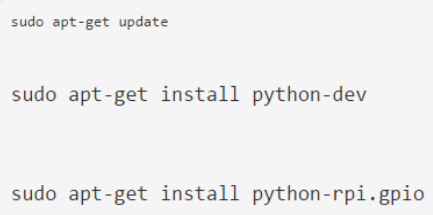

Gambar 9. Instalasi GPIO Di Raspberry Pi B

\section{Konfigurasi Fswebcam}

Library fswebcam ini akan diperlukan untuk merekam gambar (motion captures) dengan webcam C170 pada saat sensor PIR KCR7783R mendeteksi adanya gerak pada obyek dari tubuh manusia. Pada konfigurasinya webcam kamera C170 dapat digunakan kode pogram untuk 
instalasi Fswebcam yang dapat dilihat pada gambar 10, dibawah ini:

sudo opt-get install fsiveccan

\section{Gambar 10. Instalasi Fswebcam Di} Raspberry Pi

Setelah itu webcamakan ditest dengan login ke GUI (Graphical User Interface). Untuk pengecekan fungsi webcam kamera C170 agar dapat digunakan di Raspberry Pi B bisa dilakukan dengan menulis kode program dapat dilihat di gambar 11, dibawah ini:

fswebcam $-d /$ dev/video0 $-r$ 640×480 test.jpg

Gambar 11. Pengecekan Fswebcam Di Raspberry Pi

\section{Perancangan Software}

Untuk menggunakan Raspberry PiB, membutuhkan sistem operasiseperti pada windows, linux, Mac OS, di PC (Personal Computer).OS (Operating System) yang ada di PC berbeda dengan OS di Raspberry Pi.Ada banyak OS yang bisa digunakan dalam perangkat Raspberry Pi, salah satunya adalah OS Raspbian. Dalam proses penginstallan pada OS Raspbian, Raspberry Pi membutuhkan media penyimpanan (storage) sehingga sistem operasi bisa berjalan. Perangkat penyimpanan itu, biasa dikenal dengan $S D$ Card. OS Raspbian hanya akan disimpan pada $S D$ Card saat proses booting akan berlangsung. Setelah selesai proses dari installRaspbian,install GPIO, Fswebcam dan kode program. Codingprogram menggunakan aplikasi putty di windows, dengan pemrograman python.

\section{Sistem Operasi Raspbian}

Raspbian adalah sistem operasi berbasis debian (linux) yang dapat digunakan di windows untuk instalasi OS di Raspberry $\mathrm{Pi}$, yaitu dengan softwareWin32DiskImager. Kemudian, softwareakan melakukan write program OS pada perangkat Raspberry $\mathrm{Pi} B$.

Pada sistem operasi Raspbian ini sudah ada program dasar dan kelengkapan yang dapat membuat Raspberry $\mathrm{Pi}$ berjalan dengan baik. Berikut ini adalah tampilan interface dari GUI Raspberrry PiB saat selesai instalasi dapat dilihat pada gambar 12 dibawah ini [6]:

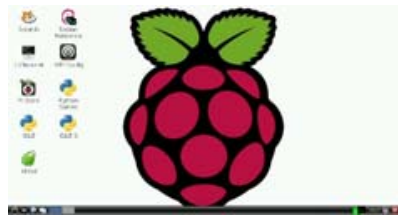

Gambar 12. Display Desktop Operating System Raspbian

\section{Bahasa Pemrograman Python}

Python adalah bahasa pemograman jenis script (scripting language) berdasarkan orientasi obyek. Python dapat digunakan untuk berbagai keperluan suatu pengembangan software yang bekerja di berbagai platform sistem operasi Raspbian.Phyton merupakan bahasa pemograman yang freeware lengkap dengan source code, debugger dan profiler, interface yang terkandung di dalamnya untuk pelayanan antarmuka, fungsi sistem, GUI (antarmuka pengguna grafis) dan basis datanya. Dibawah ini, fitur yang dimiliki python:

1. Memiliki kepustakaan yang luas; dalam distribusi python sudah disediakan suatu modul-modul, sehingga dapat mendukung sumber penelitian atau proyek ilmiah.

2. Memiliki tata bahasa yang jernih.

3. Mudah dimengerti dan dipelajari.

4. Memiliki suatu aturan layout yangberupa kode sumber (source code) yang akan memudahkan bagi 
pengecekan, pembacaan kembali dan penulisan ulang source.

5. Berorientasi pada obyek.

6. Dapat dibangun dalam bahasa pemograman bahasa $\mathrm{C} / \mathrm{C}++$ dan python [7].

\section{Secure Shell Protocol (SSH)}

SSH adalah protokol yang berjalan pada jaringan yang menjamin keamanan dari komunikasi data antar device. Untuk itu, SSH diperlukan sebagai koneksi bagi raspbian. Implementasi kode program menggunakan putty dapat dilihat di gambar 13 dibawah ini:

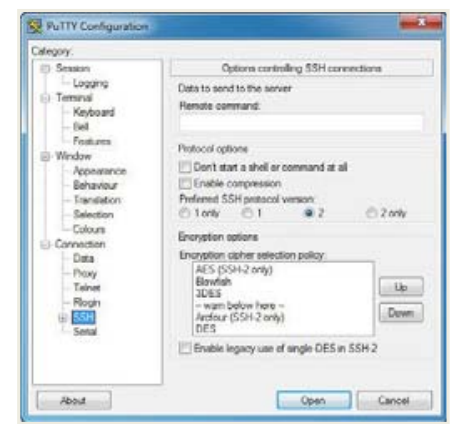

Gambar 13. SSH dengan putty

\section{Application Programming Interface (API) Twitter}

Dalam seubah twitter terdapat API (Appplication Programming Interface) yaitu aplikasi yang disediakan pihak developer twitter agar pihak developer lain dapat dengan mudah mengakses API twitter dan berfungsi sebagai jembatan aplikasi satu dan lainnya.

Berikut ini pembuatan dari API Key dan API Secret beserta tampilan API Key dan API Secret setelah dibuat dalam twitter, yang bisa dilihat dari gambar 14 dan 15 dibawah ini:

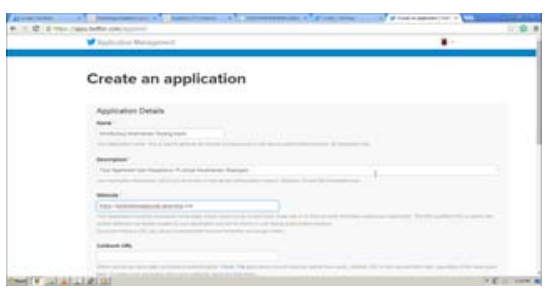

Gambar 14. Create Aplikasi API Twitter

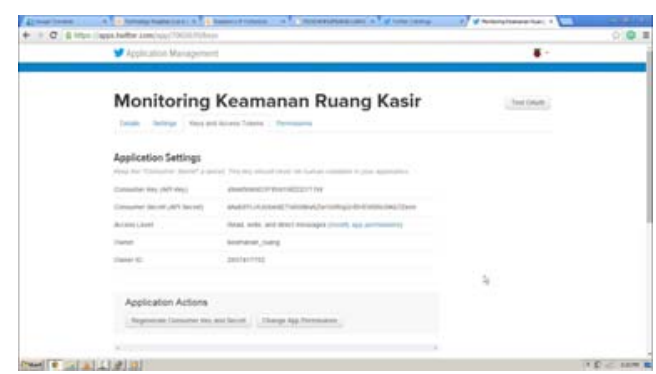

Gambar 15. Tampilan API Key dan API Secret

\section{Twitter Python (Twitton)}

Twitton adalah perancangan sistem untuk mengkonfigurasi Raspberry $\mathrm{Pi}$ dengan mengirimkan messages di device appstwiter menggunakan bahasa pemograman python. Untuk menjalankan program diperlukan aplikasi putty yang diakses dari SSH (wireless). Dibawah ini perancangan kode program sistem alat secara keseluruhan dan pengujian alat wireless suveillance camera dari twitter yang dapat dilihat dalam gambar 16 dan 17:

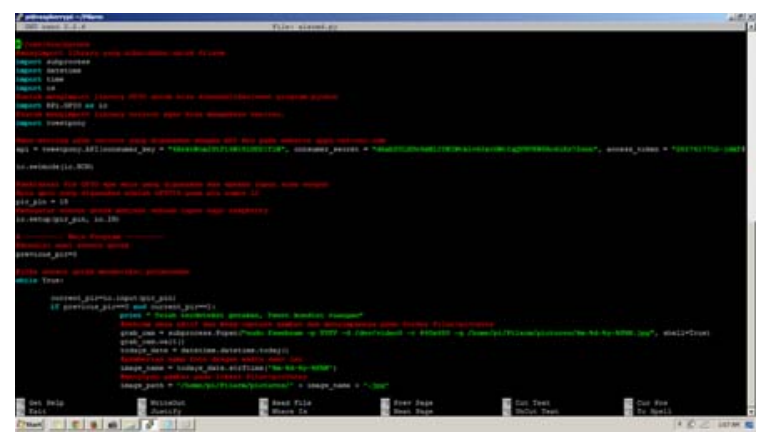

Gambar 16. Program Surveillance Camera Motion Captures 


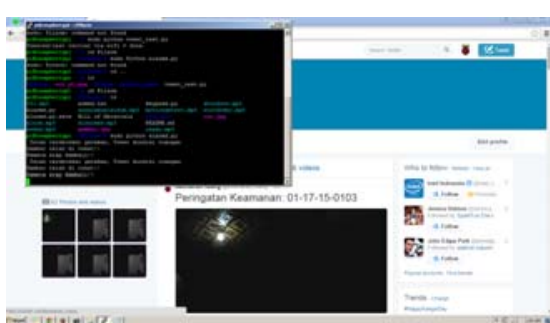

Gambar 17. Pengujian Monitoring Melalui Aplikasi Twitter

\section{KESIMPULAN}

Berdasarkan dari uraian yang dapat diambil untuk penelitian diatas, diantaranya dalam menangkap (motion captures), dengan survaillance camera yaitu sebagai berikut:

1. Menangkap gambar (captures) secara otomatis tanpa input dari operator dengan bantuan sensor PIR KCR7783R sebagai alat untuk mendeteksi gerakan manusia.

2. Pengawasan dengan sensor PIR, efektif mengurangi beban media penyimpanan karena dengan motion captures hanya menyimpan gambar disaat terjadi gerakan.

3. Raspberry Pi telah dapat membaca input dan output dari sensor PIR dan webcam terbukti saat ada gerakan maka captures kamera dapat disimpan di Raspberry Pi.

4. Program python dari Raspberry Pi berjalan dengan baik sesuai dengan fungsinya dalam menangkap obyek gerakan yang dapat di tampilkan dari perangkat twitter.

5. Twitter dapat melakukan monitoring secara real-time dari menampilkan gambar pada format .jpg dan waktu kejadian saat obyek terdeteksi pada kamera webcam.

6. Sistem monitoring berbasis internet connection berbasis jaringan wireless dalam monitoring menggunakan TP-LINK TLWN722N dengan tethering smartphones.

\section{DAFTAR PUSTAKA}

[1] Bustanul Arifin. 2013. “Aplikasi Sensor Passive Infrared (PIR) Untuk Pendeteksian Makhluk Hidup Dalam Ruang”. Jurusan Teknik Elektro, Fakultas Teknologi Industri, Tugas Akhir, Universitas Islam Sultan Agung, 2013.

[2] Gora, Oguz. 2015. "A Novel Video/Photo Recorder Using an Online Motion Sensor-Triggered Embedded System". Vocational School, Yasar University, ISDE, Vol.6 No.4, 2015.

[3] Hendra Kusumah. 2013. "Surveillance Camera Robot." Jurusan Sistem Komputer, SKRIPSI, STMIK Raharja, 2013.

[4] Nugroho Amarudita. 2012. Raspberry Pi sebagai Pengendali Web Camera Melalui Web Browser Untuk Meningkatkan Keamanan Pada PT Medarya Menara Lestari.” Jurusan Sistem Komputer, SKRIPSI, STMIK Raharja, 2012.

[5] Nursalim. 2014. "Smartphone Control Interface Melalui Web Berbasis Raspberry Pi Pada Kantor Kelurahan Cibogo Di Daerah Cisauk Kabupaten Tangerang." Jurusan Sistem Komputer, SKRIPSI, STMIK Raharja, 2014.

[6] Shadiq, Helmi Muhammad. 2014. "Perancangan Kamera Pemantau Nirkabel Menggunakan Raspberry Pi Model B”. Jurusan Teknik Elektro, Universitas Dipenogoro (UNDIP) Semarang, TRANSIENT, Vol 3, No.4, Desember 2014.

[7] Therzian R. Perkasa. 2014. "Rancang Bangun Pendeteksi Gerak Menggunakan Metode Image Subtraction Pada Single Board Computer". Jurusan Sistem Komputer, STMIK STIKOM Surabaya, JCONES, Vol. 3, No. 2, 2014. 